\title{
Trends and Variability of Daily Temperature Extremes during 1960-2012 in the Yangtze River Basin, China
}

\author{
F. Zheng ${ }^{1}$, Y. Guan ${ }^{2}$, X. Zhang ${ }^{3}$
}

The variability of surface air temperature extremes has been the focus of attention during the past several decades, and may exert a great influence on the global hydrologic cycle and energy balance through thermal forcing. Based on daily minimum temperature (TN) and maximum temperature (TX) observed by the China Meteorological Administration at 143 meteorological stations in the Yangtze River Basin (YRB), a suite of temperature indices recommended by the Expert Team on Climate Change Detection and Indices, with a primary focus on extreme events, were computed and analyzed for the period of 1960-2012 for this area. Some of the results are shown in Figure 1.
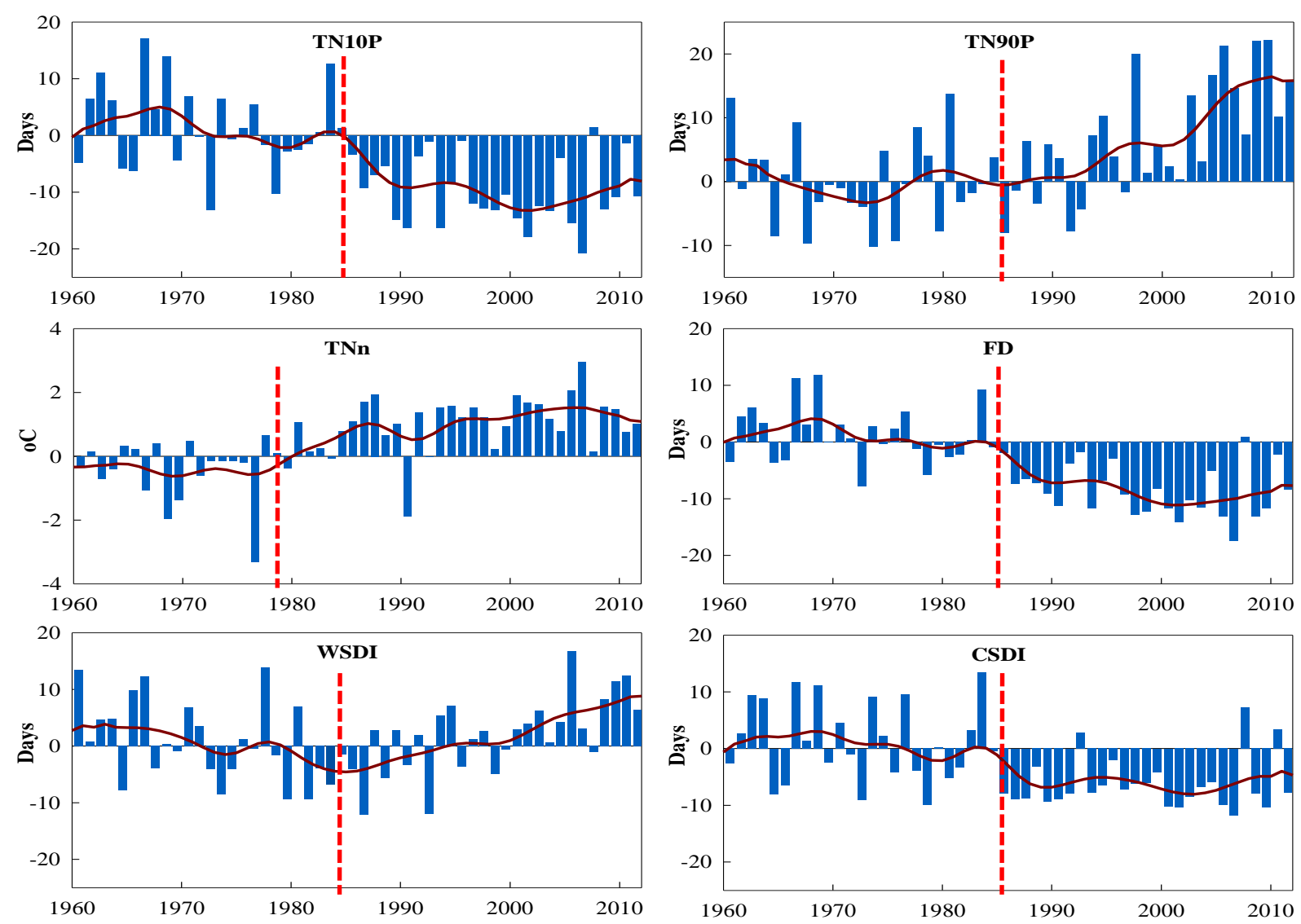

Notes: TN10P - annual count of days when daily minimum temperature <10th percentile; TN90P - annual count of days when daily minimum temperature >90th percentile; TNn - annual minimum value of daily minimum temperature; FD - annual count of days where daily minimum temperature $<0{ }^{\circ} \mathrm{C}$; WSDI - annual count of days with at least 6 consecutive days when daily maximum temperature >90th percentile; CSDI - annual count of days with at least 6 consecutive days when daily minimum temperature <10th percentile.

Figure 1. Annual anomaly series relative to the 1961-1990 mean values for temperature indices during 1960-2012 in the Yangtze River Basin. The bold solid lines are time series being smoothed by a lowpass filter.

${ }^{1}$ Fenli Zheng, Professor, Northwest A\&F University, Yangling, Shaanxi, China; ${ }^{2}$ Yinghui Guan, Ph.D. candidate, Northwest A\&F University, Yangling, Shaanxi, China; ${ }^{3}$ Xunchang (John) Zhang, Research Hydrologist, USDA-Agricultural Research Service, Grazinglands Research Laboratory, El Reno, Oklahoma, USA; Corresponding author: F. Zheng, email: $\underline{\text { flzh@ms.iswc.ac.cn. }}$ 


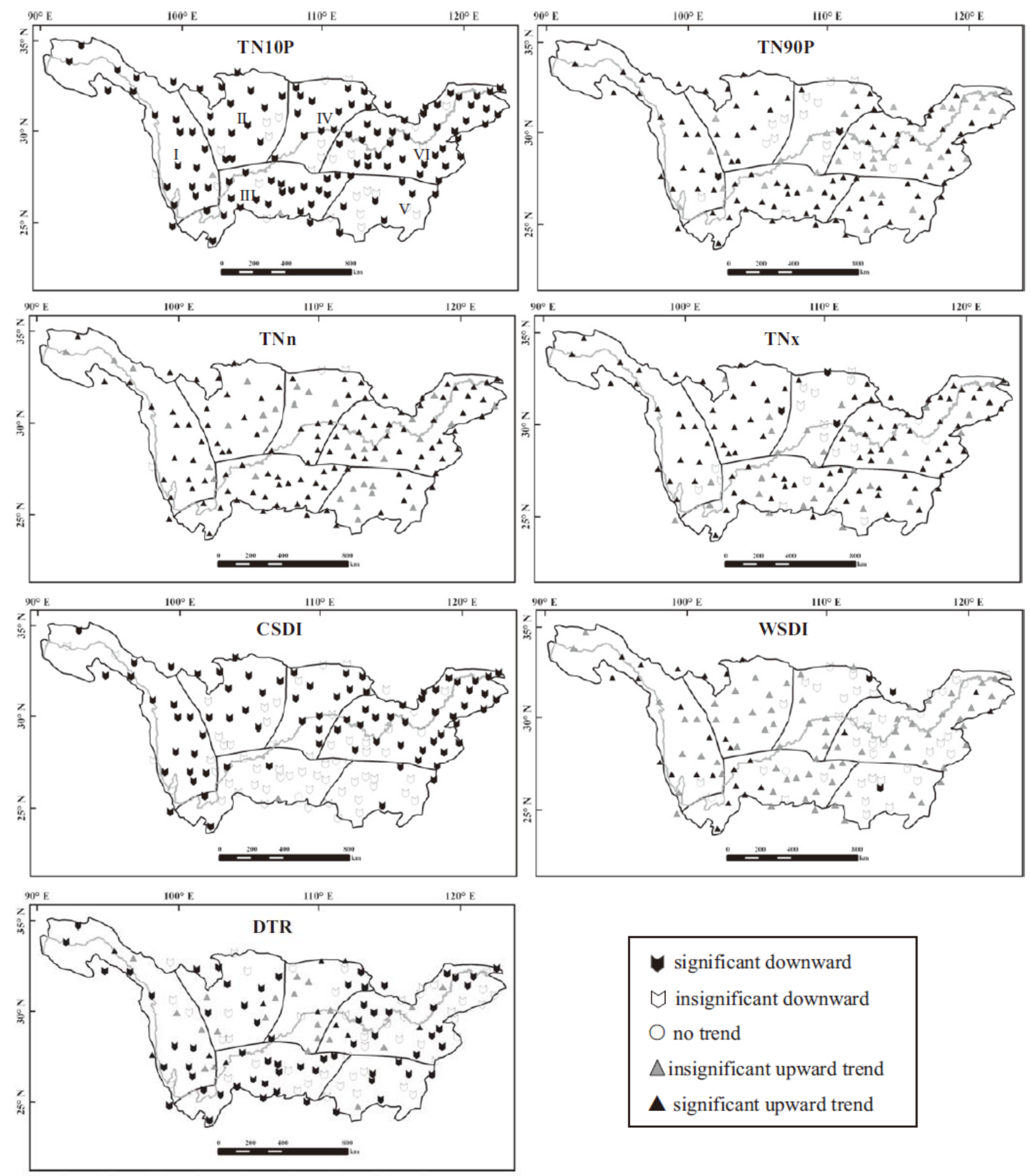

Note: DTR - annual mean difference between daily maximum temperature and daily minimum temperature.

Figure 2. Mann-Kendall trend test results for temperature indices during 1960-2012 in the Yangtze River Basin.

The results show widespread significant changes in all temperature indices associated with warming in the YRB during 1960-2012. On the whole, cold-related indices, i.e. cold nights, cold days, frost days, icing days and cold spell duration index significantly decreased by $-3.45,-1.03,-3.04,-0.42$ and -1.6 days/decade, respectively. In contrast, warm-related indices such as warm nights, warm days, summer days, tropical nights and warm spell duration index 
significantly increased by $2.95,1.71,2.16,1.05$ and 0.73 days/decade. Minimum TN, maximum $\mathrm{TN}$, minimum TX and maximum TX all increased significantly by $0.42,0.18,0.19$ and 0.14 ${ }^{\circ} \mathrm{C} /$ decade, respectively. Because of a faster increase in minimum temperature than maximum temperature, the diurnal temperature range (DTR) exhibited a significant decreasing trend of $-0.09^{\circ} \mathrm{C} /$ decade for the whole YRB during 1960-2012. However, the decreasing trends all occurred in 1960-1985, while increasing trends, though insignificant, were found in all subregions and the whole YRB during 1986-2012. Geographically, stations in the eastern Tibet Plateau and northeastern YRB showed stronger trends in almost all temperature indices (Figure 2). Time series analysis indicated that the YRB was dominated by a general cooling trend before the mid-1980s, but a warming trend afterwards. In general, the overall warming in the YRB was mainly due to the warming in 1986-2012. Strong relationships between temperature trends and elevation were detected in this study. The warming rates increased with elevation when

elevation was above $350 \mathrm{~m}$, but decreased with elevation when elevation was below $350 \mathrm{~m}$.

\section{$\underline{\text { References }}$}

IPCC. 2013. Climate change 2013: the physical science basis. Contribution of Working Group I to the Fifth Assessment Report of the Intergovernmental Panel on Climate Change. Cambridge University Press, Cambridge, United Kingdom and New York, NY, USA. 